\title{
Vibration and Damping Analysis of a Multilayered Composite Plate with a Viscoelastic Midlayer
}

\author{
Haochuan Wan, ${ }^{1,2}$ Yinong $\mathrm{Li}^{1}{ }^{1}$ and Ling Zheng ${ }^{1}$ \\ ${ }^{1}$ State Key Laboratory of Mechanical Transmission, Chongqing University, Chongqing 400044, China \\ ${ }^{2}$ Leshan Vocational \& Technical College, Leshan 614000, China \\ Correspondence should be addressed to Yinong Li; ynli@cqu.edu.cn
}

Received 2 June 2016; Accepted 14 August 2016

Academic Editor: Andras Szekrenyes

Copyright (c) 2016 Haochuan Wan et al. This is an open access article distributed under the Creative Commons Attribution License, which permits unrestricted use, distribution, and reproduction in any medium, provided the original work is properly cited.

\begin{abstract}
Based on the theory of Donnell and Kirchhoff hypothesis and by using the complex constant model of viscoelastic materials, the vibration equations of five-layered constrained damping plate are established. The transfer matrix method (TMM) is improved and used to solve equations. The improved TMM is more effective to solve complex structural vibration. The influence of layer numbers, thickness of each layer, and arrangement of materials on vibration behavior are discussed. It is proved that multilayered plates can more effectively reduce natural frequency and obtain higher structural loss factor. The loss factor increases with the number of whole layers. Symmetrical structure can obtain higher structural loss factor than one-direction structure. Uniform arrangement of viscoelastic materials and constrained materials can obtain higher structural loss factor than nonuniform arrangement. There is different optimum frequency with different material thickness, and the optimum frequency is not dependent from layer numbers.
\end{abstract}

\section{Introduction}

Viscoelastic material, with its excellent damping characteristics, can greatly dissipate vibration energy, and better damping effect can be obtained when a constrained layer is attached to them, forming a passive constrained layer damping (PCLD). The PCLD is widely used in aviation, aerospace, submarines, vehicles, and so forth, due to its simple structure, low cost, high reliability, and effectiveness in a wide temperature and frequency range. However, traditional PCLD is a three-layer constrained damping structure (i.e., host layer, viscoelastic material layer, and constrained layer), which can obviously lead to relatively large attached mass, and it is not suitable for places where light weight is required, such as in aerospace engine drum and blade. Thus optimized design on constrained damping is necessary to achieve optimal damping property with the least attached mass.

Constrained damping materials have been applied to the aerospace structures since 1960s. The pioneer work in this field could be traced back to Kerwin [1] and Ross et al. [2]; their works were extended by Mead and Markus [3], who presented the fourth- and sixth-order equation of motion governing the axial and bending vibrations of PCLD beams. Rikards et al. [4] studied the vibration and damping of laminated composite beams by using a simple Timoshenko beam finite element. Cupiał and Nizioł [5] discussed the threelayered composite plate with a viscoelastic core layer and two laminated face layers by the first-order shear deformation theory. Markuš [6] used the unconstrained passive damping treatments to damp the vibrations of thin cylindrical shell. Pan [7] studied the axisymmetrical vibration of a finite length cylindrical shell with a viscoelastic core. Alam and Asnani [8, 9] considered the vibration and damping analysis of a general multilayered cylindrical shell having an arbitrary number of orthotropic material layers and viscoelastic layers.

With the development of material science and engineering, increasing thinner damping materials can be fabricated, and multilayer constrained damping structures began to be applied to engineering. Moreira et al. [10], Matter et al. [11], and Amichi and Atalla [12] studied finite element modeling and computational method of damping structures. Xie and Shepard Jr. [13] investigated the contribution of parameters 


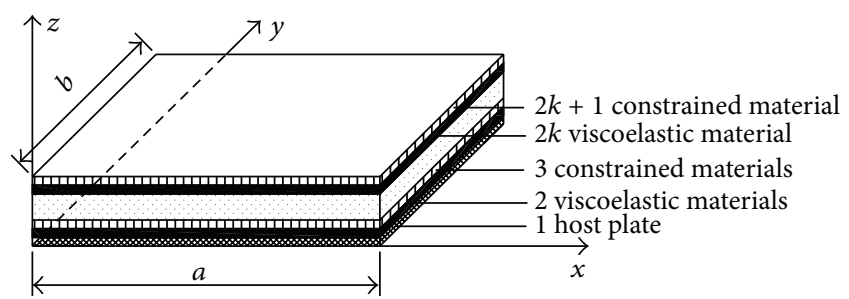

FIGURE 1: Multilayered constrained damping plate.

to damping. Chazot et al. [14] and Abdoun et al. [15] examined the responses of multilayer constrained damping structures. Yang et al. [16] considered strain energy and damping characteristics of five-layer structure while $\mathrm{Li}$ et al. [17] conducted experimentations on its damping property. Researches of multilayer constrained damping structures mainly focused on finite element method and experimental study. The dynamic behavior and internal mechanism of multilayer PCLD treatments in vibration suppression of structures are not entirely clear due to the complexity in composite structure and difficulty in describing the damping characteristics in viscoelastic material accurately.

TMM is proposed in 1920s and widely used to solve dynamic problems in structural vibration with various boundary conditions. Li et al. [18], by means of TMM, carried out theoretical analysis for the natural vibration characteristics of three-layer constrained damping plate with various boundary conditions. Xiang et al. [19, 20] extended TMM and make it convenient and effective to analyze the circular sandwich cylindrical shells partially or fully covered with PCLD treatments under almost all boundary conditions. Based on the basic assumptions of constrained damping structures, this paper developed the general equation of multilayer damping plate and improved TMM by introducing an association matrix to solve the equations. Also, the influence of the number of structure layers, thickness of materials, and various layouts on the vibration characteristics are discussed.

\section{Vibration Equation of Multilayer Constrained Damping Plate}

For a thin plate whose length is $a$ and width is $b$, when $k$ layers of damping materials and constrained materials are alternately attached to its one side or both sides, it becomes $2 k+1$ layers damping structure, as Figure 1 shows.

Here the thickness, elastic modulus, and Poisson's ratio of each layer are denoted as $h_{j}, E_{j}, \mu_{j}(j=1,2, \ldots, 2 k+1)$, respectively. For the damping layers, it is assumed that (1) only shear effect is considered; (2) there is no slippage between layers; (3) displacements between layers are continuous and the value of vertical deflection of each layer is the same. The deformation ( $2 k$ th layer) in $x$ and $y$ directions is shown in Figures 2 and 3, where $u_{j}$ and $v_{j}$ denote each layer's displacements in $x$ and $y$ directions, and $w$ is the displacement in $z$ direction.

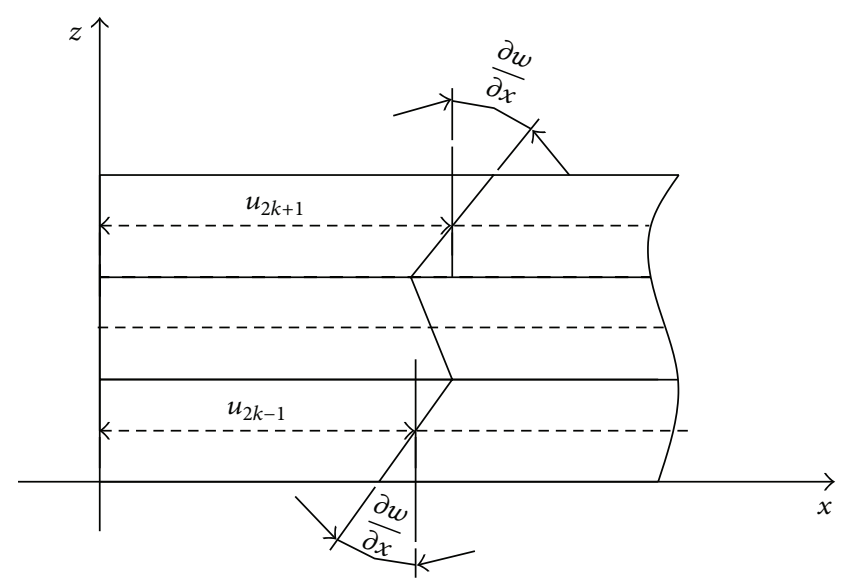

Figure 2: The deformation of $x$.

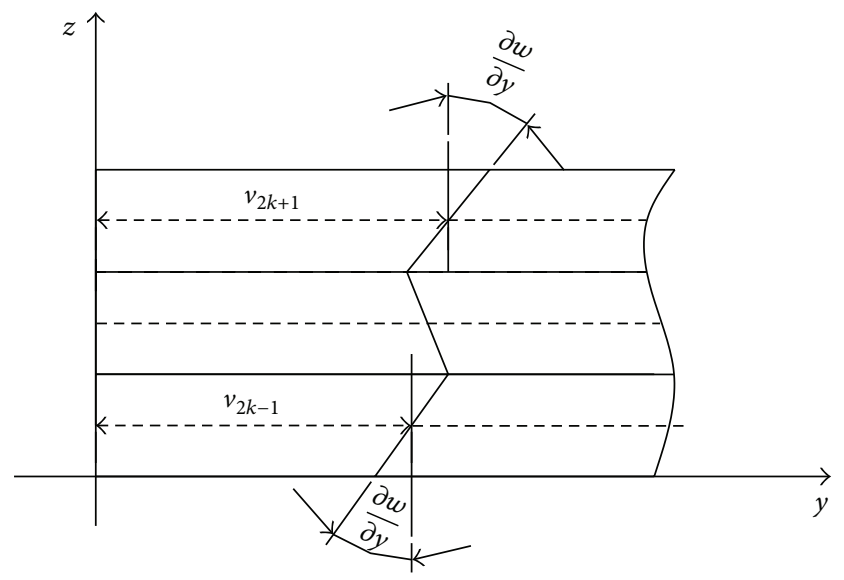

FIGURE 3: The deformation of $y$.

Because each layer is too thick, in the equations we take the middle placements as the whole layer's, as shown in Figures 2 and $3\left(u_{2 k+1}, u_{2 k-1}, v_{2 k+1}, v_{2 k-1}\right)$.

The strain column vector of the viscoelastic layer $\gamma_{2 k}=$ $\left\{\begin{array}{ll}\gamma_{x 2 k} & \gamma_{y 2 k}\end{array}\right\}^{T}$ is expressed as

$$
\begin{aligned}
& \gamma_{x 2 k}=\frac{\left(u_{2 k+1}-u_{2 k-1}-h_{2 k}^{\prime}(\partial w / \partial x)\right)}{h_{2 k}} \\
& \gamma_{y 2 k}=\frac{\left(v_{2 k+1}-v_{2 k-1}-h_{2 k}^{\prime}(\partial w / \partial y)\right)}{h_{2 k}},
\end{aligned}
$$

where $h_{2 k}^{\prime}=\left(h_{2 k-1}+h_{2 k+1}\right) / 2+h_{2 k}$.

The internal stress of the host layer, damping layer, and each constrained layer in the middle can be shown as in Figures 4-6, respectively. The internal stress of the outermost layer is the same as the host layer. 


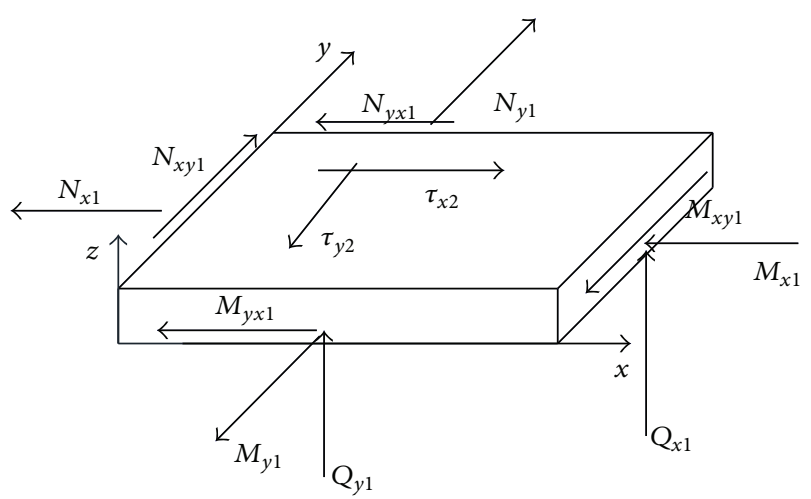

FIGURE 4: Internal stress of the host layer.

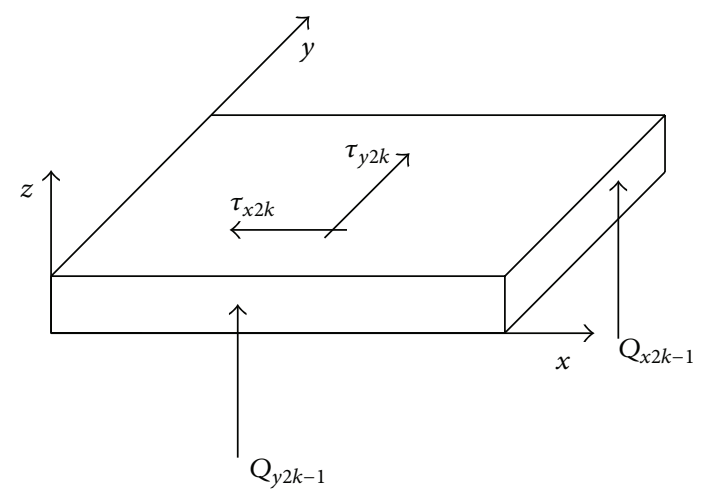

FIGURE 5: Internal stress of the damping layer.

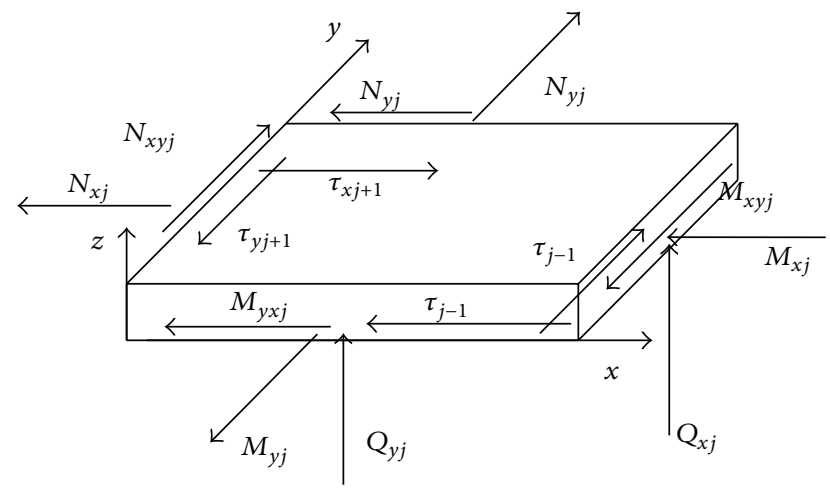

FIGURE 6: Internal stress of each constrained layer in the middle.

The 1st layer is the host layer, and the $j$ th $(j=3,5, \ldots, 2 k+$ 1) layer is the constrained layer. The internal stress can be expressed as

$$
\begin{aligned}
N_{x j} & =K_{j}\left(\frac{\partial u_{j}}{\partial x}+\mu_{j} \frac{\partial v_{j}}{\partial y}\right), \\
N_{y j} & =K_{j}\left(\mu_{j} \frac{\partial u_{j}}{\partial x}+\frac{\partial v_{j}}{\partial y}\right), \\
N_{x y j} & =K_{j} \frac{1-\mu_{j}}{2}\left(\frac{\partial u_{j}}{\partial y}+\frac{\partial v_{j}}{\partial x}\right),
\end{aligned}
$$

$$
\begin{aligned}
M_{x j} & =D_{j}\left(\frac{\partial^{2} w}{\partial x^{2}}+\mu_{j} \frac{\partial^{2} w}{\partial y^{2}}\right), \\
M_{y j} & =D_{j}\left(\mu_{j} \frac{\partial^{2} w}{\partial x^{2}}+\frac{\partial^{2} w}{\partial y^{2}}\right), \\
M_{x y j} & =D_{j}\left(1-\mu_{j}\right) \frac{\partial^{2} w}{\partial x \partial y}, \\
Q_{x j} & =\frac{\partial M_{x y j}}{\partial y}+\frac{\partial M_{x j}}{\partial x}-\frac{h_{j}}{2}\left(\tau_{x j-1}+\tau_{x j+1}\right), \\
Q_{y j} & =\frac{\partial M_{x y j}}{\partial x}+\frac{\partial M_{y j}}{\partial y}-\frac{h_{j}}{2}\left(\tau_{y j-1}+\tau_{y j+1}\right) .
\end{aligned}
$$

The vibration equations of the constrained layer are as follows:

$$
\begin{aligned}
& m_{j} \frac{\partial^{2} u_{j}}{\partial t^{2}}=\frac{\partial N_{x j}}{\partial x}+\frac{\partial N_{x y j}}{\partial y}+\tau_{x j+1}-\tau_{x j-1} \\
& m_{j} \frac{\partial^{2} v_{j}}{\partial t^{2}}=\frac{\partial N_{y j}}{\partial y}+\frac{\partial N_{x y j}}{\partial x}+\tau_{y j+1}-\tau_{y j-1} \\
& m \frac{\partial^{2} w}{\partial t^{2}}=\sum_{j=1}^{2 k+1}\left(\frac{\partial Q_{x j}}{\partial x}+\frac{\partial Q_{y j}}{\partial y}\right)
\end{aligned}
$$

where $K_{j}=E_{j} h_{j} /\left(1-\mu_{j}^{2}\right), D_{j}=E_{j} h_{j}^{3} / 12\left(1-\mu_{j}^{2}\right), m_{j}=$ $\rho_{j} h_{j}, m=\sum_{j=1}^{2 k+1} m_{j}$, and $D=\sum_{j=1}^{2 k+1} D_{j}$. There are $2 k+3$ equations in the equations above.

Substituting (1) and (2) into (3), we have

$$
\begin{aligned}
K_{j} & \left(\frac{\partial^{2} u_{j}}{\partial x^{2}}+\frac{1+\mu_{1}}{2} \frac{\partial^{2} v_{j}}{\partial x \partial y}+\frac{1-\mu_{j}}{2} \frac{\partial^{2} u_{j}}{\partial y^{2}}\right) \\
& +\frac{G_{j+1}^{*}}{h_{j+1}}\left(u_{j+2}-u_{j}-h_{j+1}^{\prime} \frac{\partial w}{\partial x}\right)-\frac{G_{j-1}^{*}}{h_{j-1}}\left(u_{j}-u_{j-2}\right. \\
& \left.-h_{j-1}^{\prime} \frac{\partial w}{\partial x}\right)=m_{j} \frac{\partial^{2} u_{j}}{\partial t^{2}}, \\
K_{j} & \left(\frac{\partial^{2} v_{j}}{\partial y^{2}}+\frac{1+\mu_{1}}{2} \frac{\partial^{2} u_{j}}{\partial x \partial y}+\frac{1-\mu_{j}}{2} \frac{\partial^{2} v_{j}}{\partial x^{2}}\right) \\
& +\frac{G_{j+1}^{*}}{h_{j+1}}\left(v_{j+2}-v_{j}-h_{j+1}^{\prime} \frac{\partial w}{\partial y}\right)-\frac{G_{j-1}^{*}}{h_{j-1}}\left(v_{j}-v_{j-2}\right. \\
& \left.-h_{j-1}^{\prime} \frac{\partial w}{\partial y}\right)=m_{j} \frac{\partial^{2} v_{j}}{\partial t^{2}}, \\
- & D\left(\frac{\partial^{4} w}{\partial x^{4}}+\frac{\partial^{4} w}{\partial y^{4}}+2 \frac{\partial^{4} w}{\partial x^{2} \partial y^{2}}\right)-\sum_{i=1}^{k} \frac{h_{2 k}^{\prime} G_{2 k}^{*}}{h_{2 k}}\left(\frac{\partial u_{2 k+1}}{\partial x}\right. \\
& \left.+\frac{\partial u_{2 k-1}}{\partial x}+\frac{\partial v_{2 k+1}}{\partial y^{2}}-\frac{\partial v_{2 k-1}}{\partial y}\right)+\sum_{i=1}^{k} \frac{\partial_{2 k}^{\prime} G_{2 k}^{*}}{h_{2 k}}\left(\frac{\partial^{2} w}{\partial x^{2}}\right.
\end{aligned}
$$

where there are $2 k+3$ equations and $2 k+3$ variables in (4). 
2.1. Solutions of the Equations. The TMM is widely used in the structural vibration for its good boundary conditions adaptability. The improved TMM is more convenient to obtain the first-order derivative of the state vector. Therefore it is adopted to solve the equations in this paper.

When the boundary condition of $y$ direction is simply support condition at two ends, the solution of (4) can be written as

$$
\begin{aligned}
& u_{j}(x, y, t)=U_{j}(x) \sin \frac{n \pi y}{b} e^{i \omega^{*} t}, \\
& v_{j}(x, y, t)=V_{j}(x) \cos \frac{n \pi y}{b} e^{i \omega^{*} t}, \\
& w(x, y, t)=W(x) \sin \frac{n \pi y}{b} e^{i \omega^{*} t},
\end{aligned}
$$

where $n$ is the vibration wave number in $y$ direction, $\omega^{*}$ is the complex frequency, $\omega^{*}=\omega 2(1+\eta i)$, and $\omega$ is natural circular frequency of vibration. $\eta$ is the structural loss factor. $U_{j}(x)$ and $V_{j}(x)$ are the displacement functions of the $j$ th layer in $x$ and $y$ directions, and $W(x)$ is the displacement function in $z$ direction.

Substituting (5) into (4), we have

$$
\begin{aligned}
& \frac{\partial^{2} U_{j}}{\partial x^{2}}=-\frac{G_{j-1}^{*}}{K_{j} h_{j-1}} U_{j-2} \\
& +\left(\frac{1-\mu_{j}}{2}\left(\frac{n \pi}{b}\right)^{2}+\frac{G_{j-1}^{*}}{K_{j} h_{j-1}}+\frac{G_{j+1}^{*}}{K_{j} h_{j+1}}-\frac{m_{j} \omega^{* 2}}{K_{j}}\right) \\
& \cdot U_{j}+\frac{1+\mu_{j}}{2} \frac{n \pi}{b} \frac{\partial V_{j}}{\partial x}-\frac{G_{j+1}^{*}}{K_{j} h_{j+1}} U_{j+2} \\
& -\left(\frac{G_{j-1}^{*} h_{j-1}^{\prime}}{K_{j} h_{j-1}}-\frac{G_{j+1}^{*} h_{j+1}^{\prime}}{K_{j} h_{j+1}}\right) \frac{\partial W}{\partial x}, \\
& \frac{\partial^{2} V_{j}}{\partial x^{2}}=-\frac{2}{1-\mu_{j}} \frac{G_{j-1}^{*}}{K_{j} h_{j-1}} V_{j-2}-\frac{1+\mu_{j}}{1-\mu_{j}} \frac{n \pi}{b} \frac{\partial U_{j}}{\partial x} \\
& +\frac{2}{1-\mu_{j}}\left(\left(\frac{n \pi}{b}\right)^{2}+\frac{G_{j-1}^{*}}{K_{j} h_{j-1}}+\frac{G_{j+1}^{*}}{K_{j} h_{j+1}}-\frac{m_{j} \omega^{* 2}}{K_{j}}\right) \\
& \cdot V_{j}-\frac{2}{1-\mu_{j}} \frac{G_{j+1}^{*}}{K_{j} h_{j+1}} V_{j+2} \\
& -\frac{2}{1-\mu_{j}}\left(\frac{G_{j-1}^{*} h_{j-1}^{\prime}}{K_{j} h_{j-1}}-\frac{G_{j+1}^{*} h_{j+1}^{\prime}}{K_{j} h_{j+1}}\right) \frac{n \pi}{b} W, \\
& \frac{\partial^{4} W}{\partial x^{4}}=\frac{1}{D} \sum_{j=1}^{2 k+1}\left(\frac{h_{j+1}^{\prime} G_{j+1}^{*}}{h_{j+1}}-\frac{h_{j-1}^{\prime} G_{j-1}^{*}}{h_{j-1}}\right) \frac{\partial U_{j}}{\partial x}+\frac{1}{D} \\
& \cdot \sum_{j=1}^{2 k+1}\left(\frac{h_{j-1}^{\prime} G_{j-1}^{*}}{h_{j-1}}-\frac{h_{j+1}^{\prime} G_{j+1}^{*}}{h_{j+1}}\right) V_{j}+2\left(\frac{n \pi}{b}\right)^{2} \frac{\partial^{2} W}{\partial x^{2}} \\
& +\left(\frac{1}{D} m \omega^{* 2}-\left(\frac{n \pi}{b}\right)^{4}\right) W-\frac{1}{D}\left(\left(\frac{n \pi}{b}\right)^{2}+\frac{\partial^{2} W}{\partial x^{2}}\right) \\
& \cdot \sum_{j=1}^{2 k+1}\left(\frac{h_{j-1}^{\prime} G_{j-1}^{*}}{h_{j-1}}-\frac{h_{j+1}^{\prime} G_{j+1}^{*}}{h_{j+1}}\right) \text {. }
\end{aligned}
$$

Boundary conditions are as follows:

$$
\left.\begin{array}{l}
U_{j}=0 \\
\text { or } N_{x j}=\frac{\partial U_{j}}{\partial x}-\mu_{j} \frac{n \pi}{b} V_{j}=0, \\
V_{j}=0 \\
\text { or } N_{x y j}=\frac{\partial V_{j}}{\partial x}+\frac{n \pi}{b} U_{j}=0, \\
W=0 \\
\text { or } Q_{x}=D \frac{\partial^{2} w}{\partial x^{2}}-\sum_{j=1}^{2 k+1} D_{j} \mu_{j}\left(\frac{n \pi}{b}\right)^{2}=0, \\
\frac{\partial W}{\partial x}=0 \\
\left.\quad+\left(D_{j}\left(2-\mu_{j}\right)\left(\frac{n \pi}{b}\right)^{2}\right)\right) \frac{\partial w}{\partial x}=0 . \\
\quad-\sum_{j=1}^{2 k+1}\left(\sum_{j=1}^{2 k+1}\left(\frac{G_{j+1}^{*} h_{j+1}^{\prime}}{h_{j+1}}-\frac{G_{j-1}^{*} h_{j-1}^{\prime}}{h_{j-1}^{\prime}}\right) U_{j}+D \frac{\partial^{3} w}{\partial x^{3}}\right. \\
h_{j+1}
\end{array}\right)^{2}
$$

In $[19,20]$, state vectors are selected based on boundary conditions, which is convenient when the state vector has relatively less elements. However, when the state vector has more elements, the first-order differential of the state vector is hard to obtain. In this paper, the state vector and the boundary conditions are defined separately, and an association matrix is introduced to correlate them.

State vector is defined as

$$
\zeta(x)=\left[U_{j}, \frac{\partial U_{j}}{\partial x}, V_{j}, \frac{\partial V_{j}}{\partial x}, W, \frac{\partial W}{\partial x}, \frac{\partial^{2} W}{\partial x^{2}}, \frac{\partial^{3} W}{\partial x^{3}}\right]^{T} .
$$

Boundary condition vector is

$$
\xi(x)=\left[U_{j}, N_{j}, V_{j}, N_{x y j}, W, Q_{x}, \frac{\partial W}{\partial x}, M_{x}\right]^{T} .
$$

Then we have

$$
\boldsymbol{\xi}(x)=A \zeta(x)
$$

where $A$ is the association matrix.

$$
\frac{\partial \zeta(x)}{\partial x}=F \zeta(x), \quad \zeta(x)=e^{F x} \zeta(0),
$$

where $F$ and $A$ are $4 k+8$-order square matrices and can be derived from (6) and (7) and detail format of $F$ and $A$ can be seen in Appendix.

$$
\begin{aligned}
& \xi(a)=A \zeta(a)=A e^{F a} \zeta(0)=A e^{F a} A^{-1} A \zeta(0), \\
& \xi(a)=T \xi(0)=T A \zeta(0) .
\end{aligned}
$$


TABLE 1: Dynamical results of three- and five-layered constrained damping plate.

\begin{tabular}{lllccccc}
\hline & & \multicolumn{2}{c}{ Results } \\
\multicolumn{2}{c}{$p, n$} & \multicolumn{2}{c}{ Three layers of [21] } & \multicolumn{2}{c}{ Five layers by proposed method } & \multicolumn{2}{c}{ Five layers by FEM } \\
& & $f(\mathrm{~Hz})$ & $\eta$ & $f(\mathrm{~Hz})$ & $\eta$ & $f(\mathrm{~Hz})$ & $\eta$ \\
\hline \multirow{2}{*}{$p=1$} & $n=1$ & 60.2 & 0.190 & 61.6 & 0.188 & 57.4 & 0.190 \\
& $n=2$ & 130.4 & 0.199 & 130.2 & 0.243 & 126.9 & 0.247 \\
\hline \multirow{2}{*}{$p=2$} & $n=1$ & 115.2 & 0.203 & 115.9 & 0.239 & 112.0 & 0.241 \\
& $n=2$ & 178.5 & 0.181 & 173.9 & 0.243 & 170.4 & 0.238 \\
\hline \multirow{2}{*}{$p=31$} & $n=1$ & 195.4 & 0.174 & 189.0 & 0.240 & 186.5 & 0.232 \\
& $n=2$ & 255.0 & 0.151 & 240.6 & 0.226 & 238.5 & 0.222 \\
\hline$p=4$ & $n=3$ & 456.5 & 0.102 & 407.7 & 0.176 & 409.9 & 0.171 \\
\hline$p=5$ & $n=1$ & 435.3 & 0.105 & 390.4 & 0.181 & 391.1 & 0.180 \\
\hline
\end{tabular}

$p$ in this table stands for the vibration order in $x$ direction.

From (12) and (13), the transfer matrix $T$ can be obtained:

$$
T=A e^{F a} A^{-1} \text {. }
$$

2.2. Numerical Example. To verify the validity of the improved TMM, the three-layer damping plate with simple support at four ends from [21] is adopted as an example; its geometrical and physical parameters are as follows.

$a=0.3048 \mathrm{~m}, b=0.3480 \mathrm{~m}, h_{1}=h_{3}=0.762 \mathrm{~mm}, h_{2}=$ $0.254 \mathrm{~mm}, E_{1}=E_{3}=6.89 \times 10^{10} \mathrm{pa}, \rho_{1}=\rho_{3}=2.74 \times 10^{3} \mathrm{~kg} /$ $\mathrm{m}^{3}, \rho_{2}=0.999 \times 10^{10} \mathrm{~kg} / \mathrm{m}^{3}, \mu_{1}=\mu_{3}=0.3$, and $G_{2}^{*}=0.896 \times$ $(1+0.5) \times 10^{6} \mathrm{pa}$.

The damping layer and the constrained layer are evenly divided into two layers, respectively, and they are attached to the host layer alternately in order to form the fivelayer constrained damping plate. The overall amount of constrained damping material attached to the five-layer plate is the same as that of three-layer plate which is the numerical example. The natural frequency and loss factor of both threelayer plate and five-layer plate are calculated, respectively.

For the five-layer plate, $F, A$, and $T$ are 16-order square matrix; boundary conditions of both ends for the simply supported plate are given as

$$
\begin{aligned}
& \xi(0)=\left[U_{1}, 0,0, N_{x y 1}, U_{3}, 0,0, N_{x y 3}, U_{5}, 0,0, N_{x y 5}, 0, Q_{x},\right. \\
& \left.\frac{\partial W}{\partial x}, 0\right]^{T}, \\
& \xi(a)=\left[U_{1}, 0,0, N_{x y 1}, U_{3}, 0,0, N_{x y 3}, U_{5}, 0,0, N_{x y 5}, 0, Q_{x},\right. \\
& \left.\frac{\partial W}{\partial x}, 0\right]^{T} .
\end{aligned}
$$

To satisfy the boundary conditions, it is required that $\operatorname{det}\left(T^{\prime}=T([2,3,6,7,10,11,13,16],[1,4,5,8,9,12,14,15])\right)$ $=0$.

The natural frequency and loss factor can be obtained by solving the equations, and $T^{\prime}$ varies with different boundary conditions.
The natural frequency and loss factor are calculated by both the proposed method and commercial finite element method (FEM) software ANSYS, and the results are shown in Table 1.

As can be seen from Table 1,

(1) the results from the proposed method are very close to that of the ANSYS software, demonstrating the correctness of the proposed method;

(2) compared to the three-layer plate, on condition that the overall thickness and attached mass are the same, the five-layer plate can achieve lower natural frequency and higher loss factor and hence better damping effect.

\section{Influence of Material Parameters on the Vibration}

In order to examine the damping performance of multilayer constrained plate, influence of various material layers and different kinds of layouts on the vibration characteristics is calculated, and vibration characteristics of multilayer constrained damping plate under various boundary conditions are also worked out, which accordingly demonstrated the universality of the results.

3.1. Vibration Characteristics of Constrained Damping Plate with Various Layers. Dividing the damping material in the numerical example evenly into 2 layers, 3 layers, 4 layers, and 5 layers and attaching them to the host layer, then 5-layer, 7layer, 9-layer, and 11-layer constrained damping plates come into being.

From Figures 7-12, we can see that

(1) with the number of layers increasing, the natural frequency of the multilayer structure becomes slightly lower;

(2) the loss factor increases with the number of layers going up, which is more obvious in the high-order vibrations. 


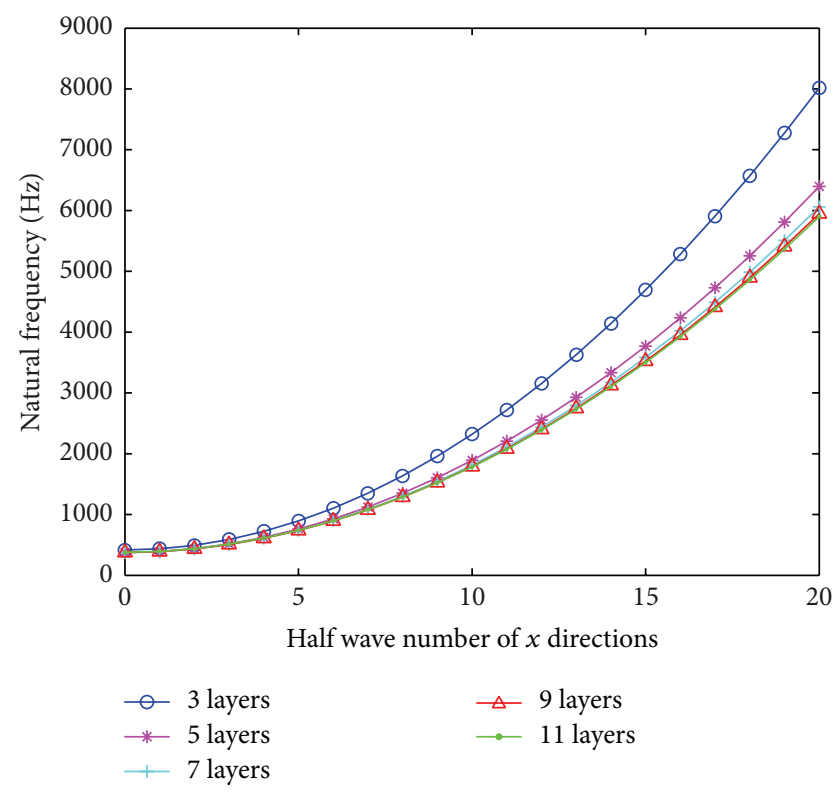

FIGURE 7: The natural frequency of constrained damping plate with various layers $(n=5)$.

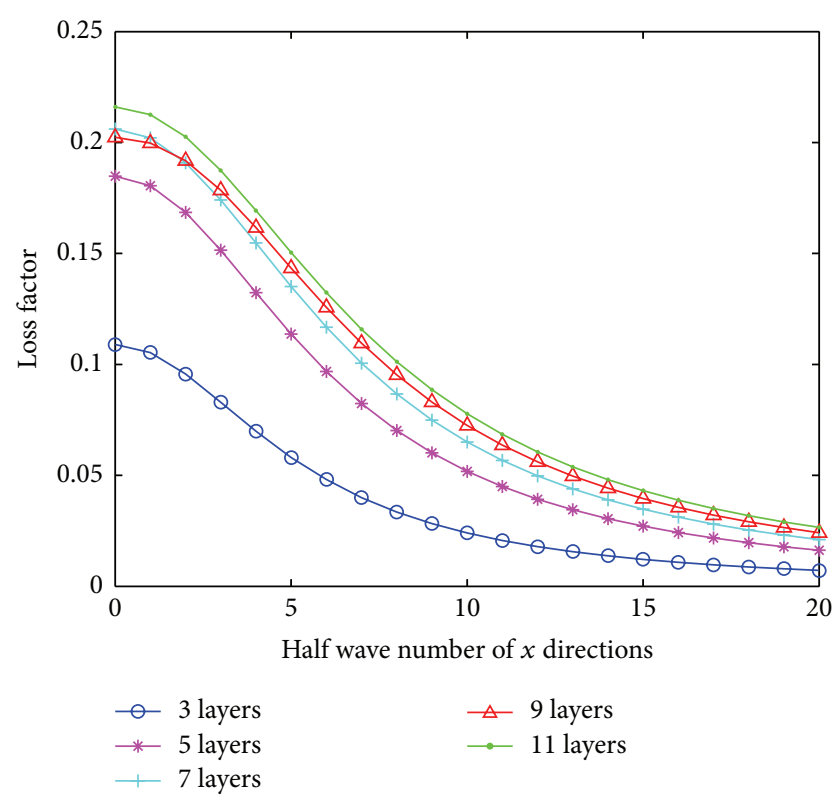

FIGURE 8: The loss factor of constrained damping plate with various layers $(n=5)$.

3.2. Influence of Various Arrangement on the Vibration Characteristics of Constrained Damping Plate. For 5-layer constrained damping plate, 5 layouts can be obtained depending on attaching constrained layers and damping layers onto one side (single side) or two sides (double sides) of the host layer and on whether the thicknesses of the 2 constrained layers and 2 damping layers are equal or not. They are uniform layout, single side nonuniform layouts (including the thicker outer layer layout and thicker inner layer layout), symmetrically uniform layout, and symmetrically nonuniform layout.

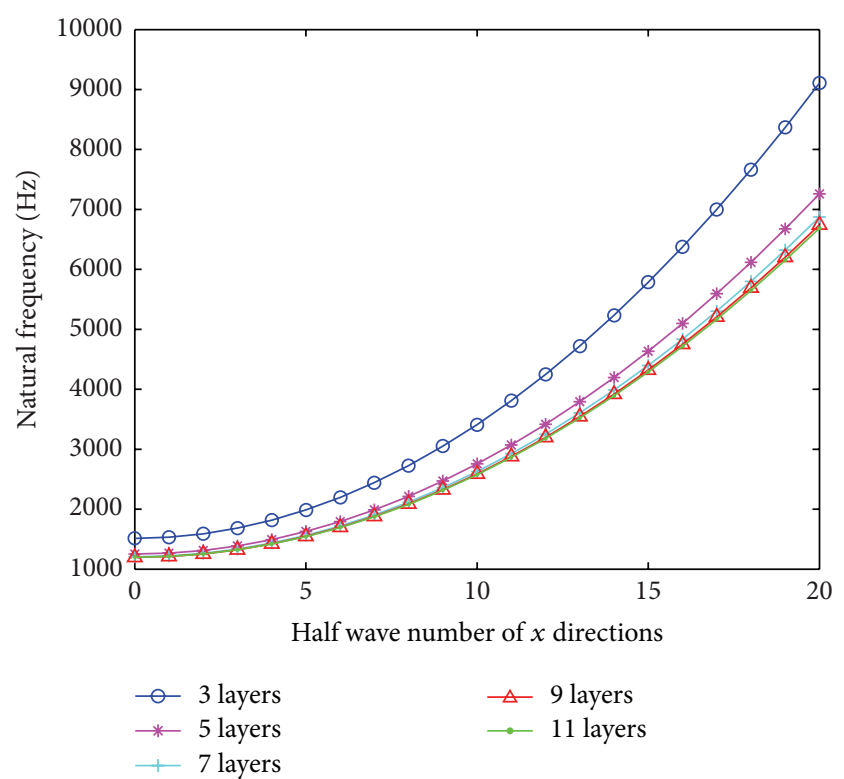

FIGURE 9: The natural frequency of constrained damping plate with various layers $(n=10)$.

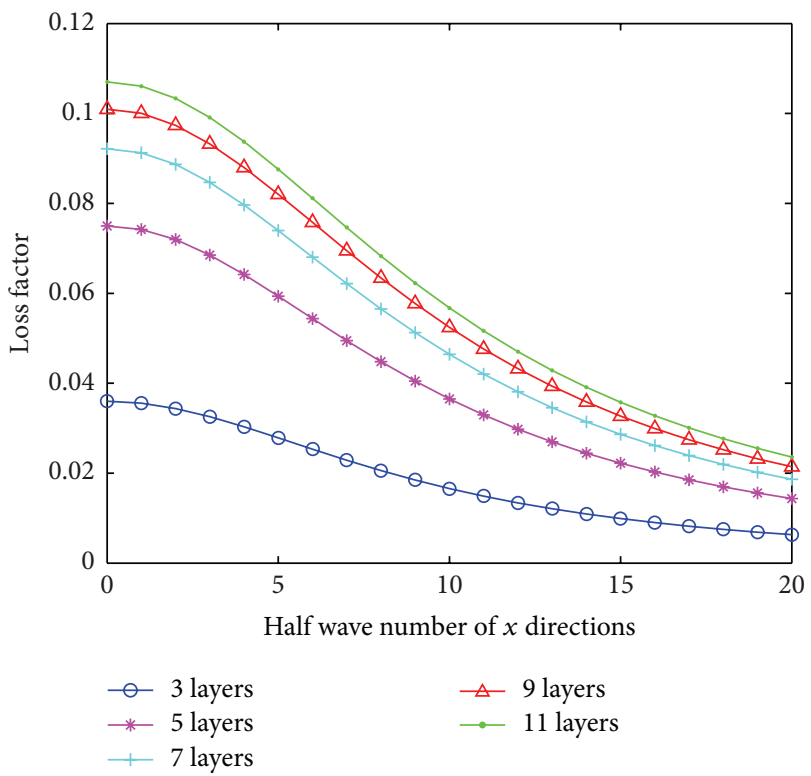

FIGURE 10: The loss factor of constrained damping plate with various layers $(n=10)$.

The natural frequency and loss factor vary with different arrangement, as shown in Figures 13 and 14.

3.3. Influence of the Thickness of Damping Material and Constrained Material on the Damping Performance. Constrained damping design can enhance the vibration resistance of structure; meanwhile, it brings attached mass to the structures. Particularly, the increase of the constrained layer can greatly raise the weight of the structures, which is adverse to some light weight structures. Therefore, it is necessary to study the 


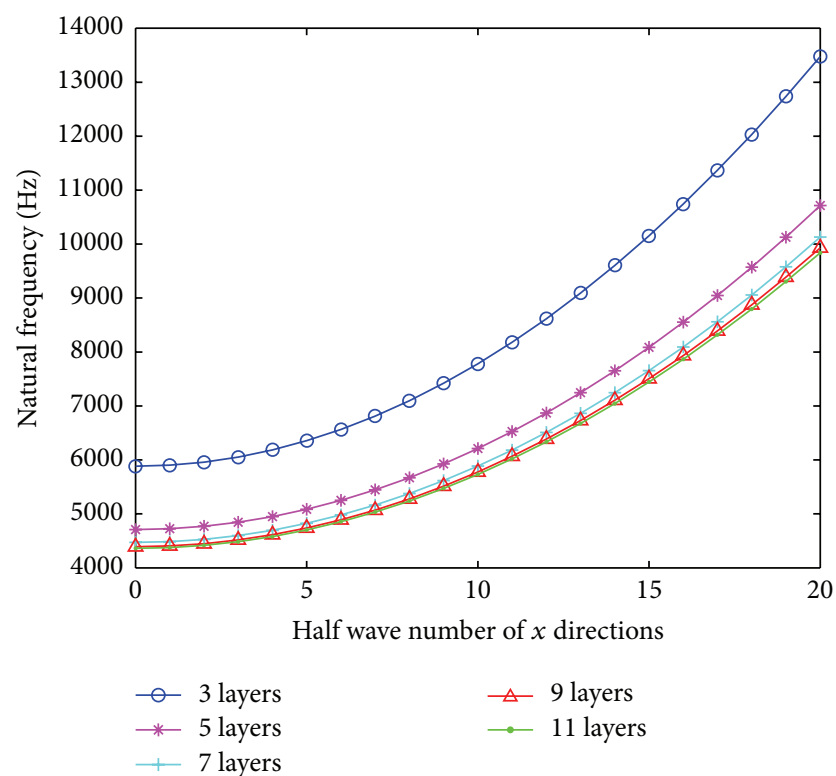

FIGURE 11: The natural frequency of constrained damping plate with various layers $(n=20)$.

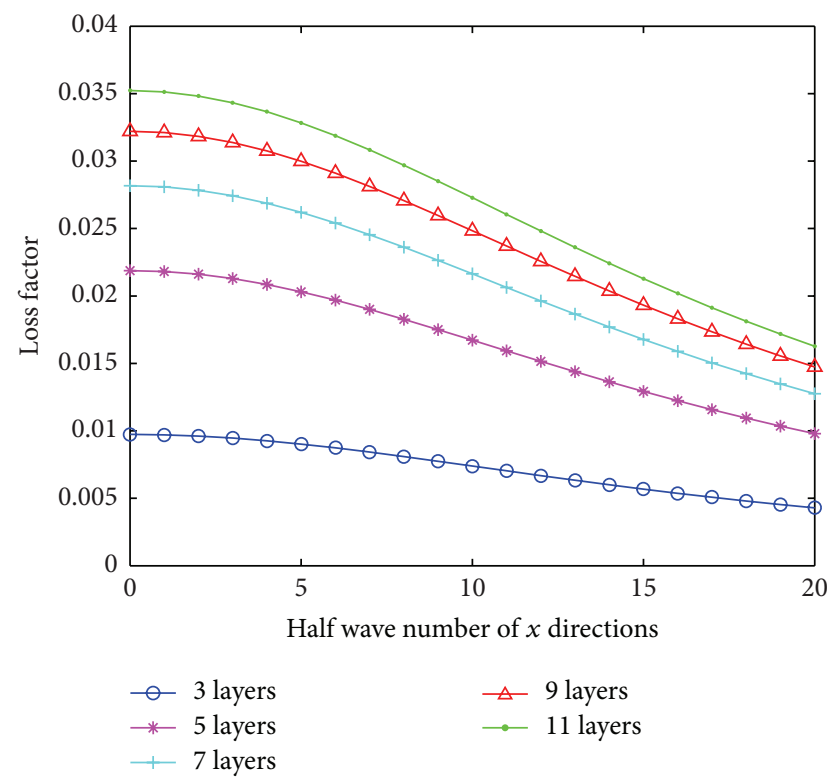

FIGURE 12: The loss factor of constrained damping plate with various layers $(n=20)$.

influence of material thickness on the vibration resistance of structures. Figures 15-18 have shown the variation of loss factor with the increase of the thickness of constrained material $(\mathrm{cm})$ and viscoelastic damping material $(\mathrm{vm})$.

Figures 15-18 illustrate that

(1) it is not that the thicker the materials, the larger the loss factor; there exists reasonable material thickness combination for different layers;

(2) with reasonable thickness, higher loss factor can be obtained with smaller attached mass.

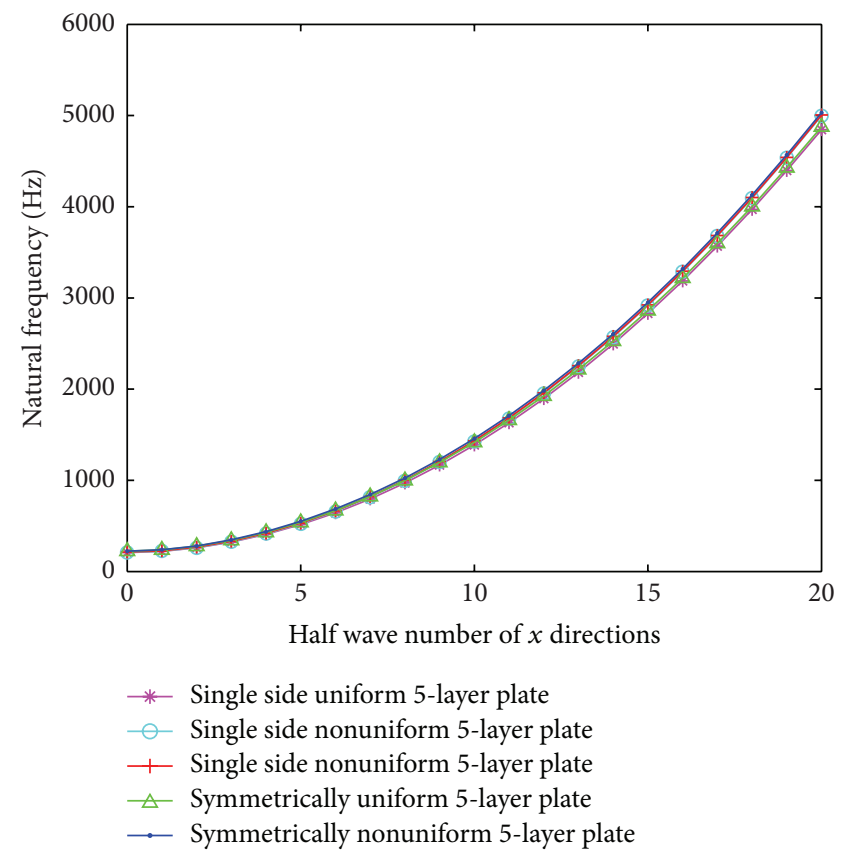

FIGURE 13: The natural frequency of five-layered constrained damping plate with various arrangement.

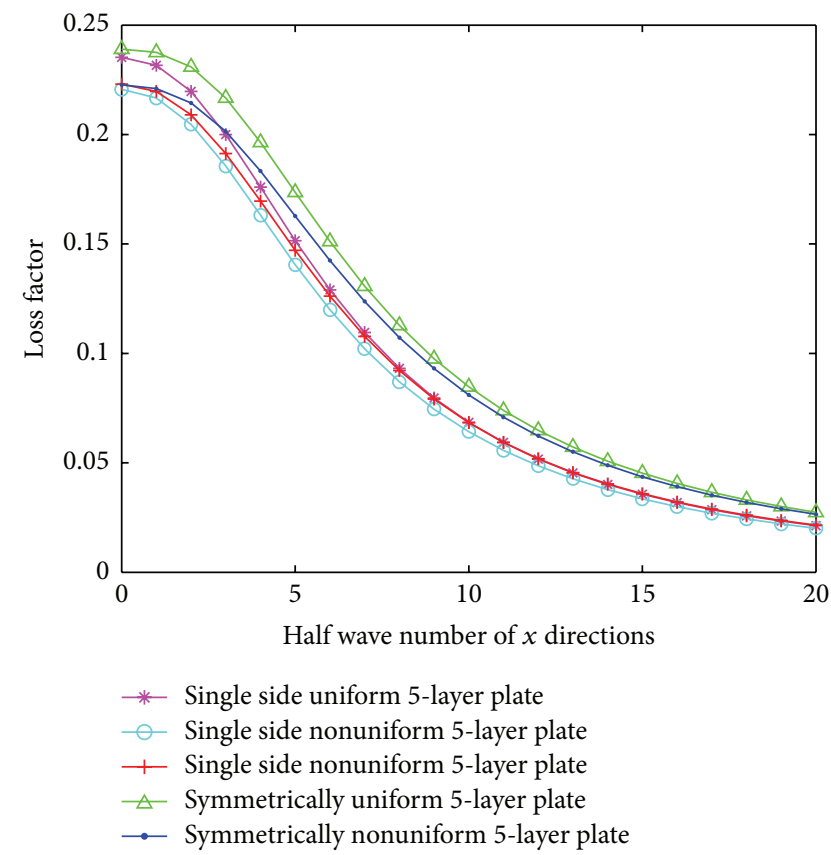

FIGURE 14: The loss factor of five-layered constrained damping plate with various arrangement.

\section{Conclusion}

The vibration and damping characteristics of multilayered constrained damping plate are investigated by using improved TMM. The natural frequencies and loss factor of constrained damping plate with various layers are calculated. The influence of layer numbers, thickness of each layer, and 


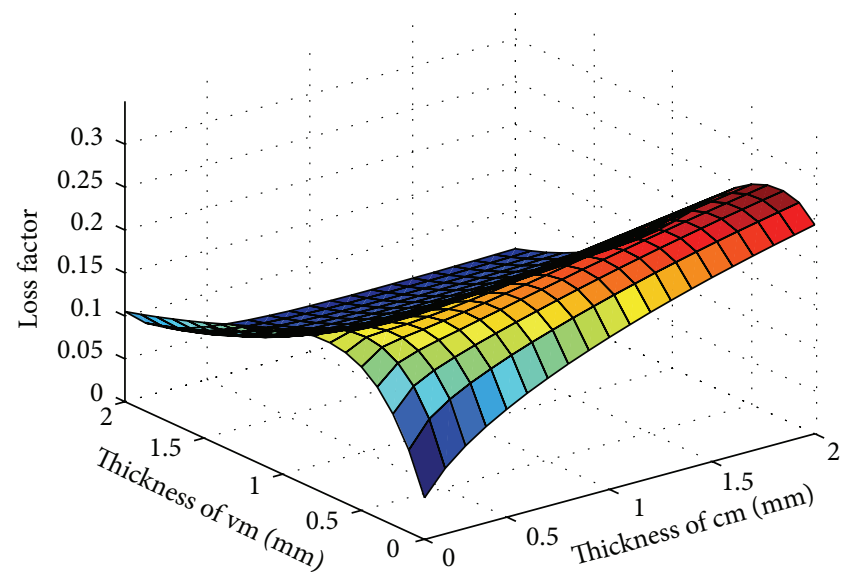

FIGURE 15: Influence of thickness on the loss factor in 3-layer structure.

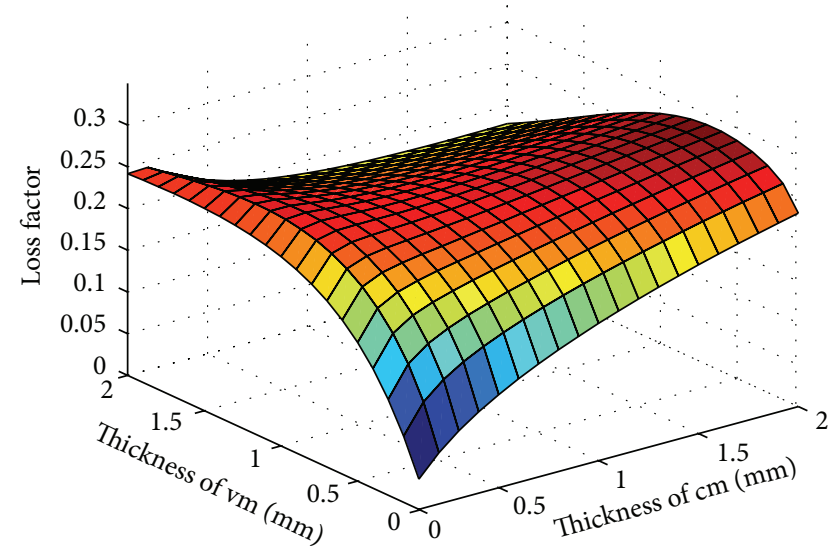

FIGURE 16: Influence of thickness on the loss factor in 5-layer structure.

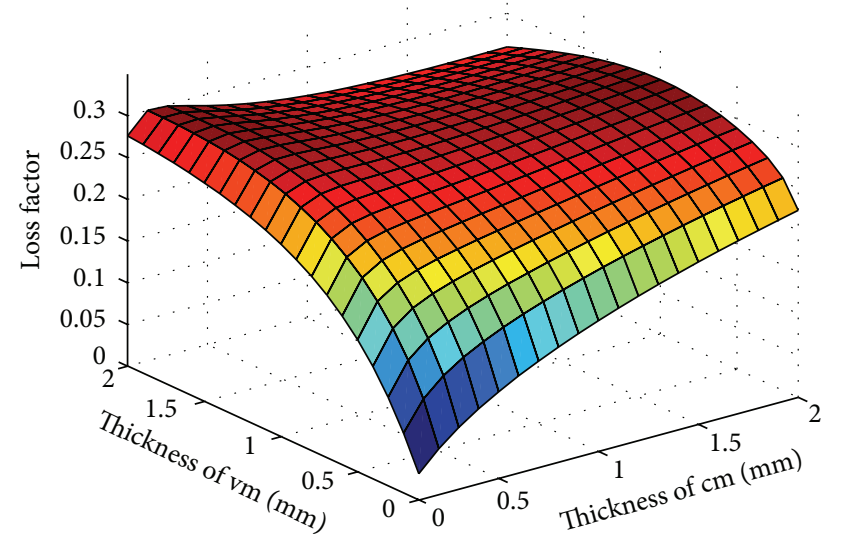

FIGURE 17: Influence of thickness on the loss factor in 7-layer structure.

arrangement of materials on vibration behavior are discussed. The following conclusions can be drawn from this paper:

(1) Multilayer structure can achieve better damping effect. Although the more the layers are, the better

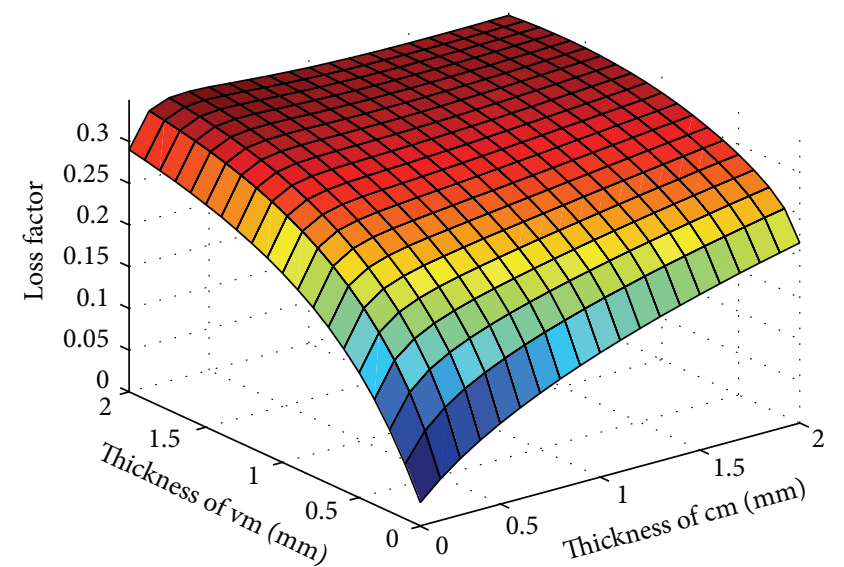

FIGURE 18: Influence of thickness on the loss factor in 11-layer structure.

the damping effect is, the loss factor increases only slightly when the number of layers attains a certain value. Thus we do not need to design too many layers.

(2) When choosing the thickness of damping material and constrained material, one should first determine the frequency range he is aiming at and obtain the optimal thickness by calculation with three-layer structure.

(3) When arranging the damping material and constrained material, the thickness of each viscoelastic layer should be equal and the thickness of each constrained layer should be equal too.

(4) The proposed method shows some advantages in terms of accuracy and efficiency over FEM and traditional numerical computation, especially in solving multispan and multilayer structure problems.

\section{Appendix}

Taking the 5-layer plate as an example, $k=2$ (2 layers of viscoelastic materials), $F$ and $A$ are both 16 -order matrices, in which

$$
\begin{aligned}
& F_{2,1}=\frac{\left(1-\mu_{1}\right)}{2}\left(\frac{n \pi}{b}\right)^{2}+\frac{G_{2}^{*}}{K_{1} h_{2}}-\frac{m_{1} \omega^{* 2}}{K_{1}}, \\
& F_{2,4}=\frac{1+\mu_{1}}{2} \frac{n \pi}{b} \\
& F_{2,5}=-\frac{G_{2}^{*}}{K_{1} h_{2}} \\
& F_{2,14}=\frac{G_{2}^{*} h}{K_{1} h_{2}}, \\
& F_{4,2}=-\frac{1+\mu_{1}}{1-\mu_{1}} \frac{n \pi}{b}
\end{aligned}
$$




$$
\begin{aligned}
& F_{4,3}=\frac{2}{1-\mu_{1}}\left(\left(\frac{n \pi}{b}\right)^{2}+\frac{G_{2}^{*}}{K_{1} h_{2}}-\frac{m_{1} \omega^{* 2}}{K_{1}}\right), \quad F_{12,13}=-\frac{2}{1-\mu_{5}} \frac{G_{4}^{*} h^{\prime}}{K_{5} h_{4}} \frac{n \pi}{b} \\
& F_{4,7}=-\frac{2}{1-\mu_{1}} \frac{G_{2}^{*}}{K_{1} h_{2}} \\
& F_{4,13}=\frac{2}{1-\mu_{1}} \frac{G_{2}^{*} h}{K_{1} h_{2}} \frac{n \pi}{b} \\
& F_{16,2}=\frac{1}{D_{1}+D_{3}+D_{5}} \frac{h G_{2}^{*}}{h_{2}} \\
& F_{16,3}=-\frac{1}{D_{1}+D_{3}+D_{5}} \frac{h G_{2}^{*}}{h_{2}} \frac{n \pi}{b}, \\
& F_{6,1}=-\frac{G_{2}^{*}}{K_{3} h_{2}} \\
& F_{6,5}=\frac{1-\mu_{3}}{2}\left(\frac{n \pi}{b}\right)^{2}+\frac{G_{2}^{*}}{K_{3} h_{2}}+\frac{G_{4}^{*}}{K_{3} h_{4}}-\frac{m_{3} \omega^{* 2}}{K_{3}} \\
& F_{6,8}=\frac{1+\mu_{3}}{2} \frac{n \pi}{b}, \\
& F_{6,9}=-\frac{G_{4}^{*}}{K_{3} h_{4}}, \\
& F_{6,14}=-\frac{G_{2}^{*} h}{K_{3} h_{2}}+\frac{G_{4}^{*} h^{\prime}}{K_{3} h_{4}}, \\
& F_{8,3}=-\frac{2}{1-\mu_{3}} \frac{G_{2}^{*}}{K_{3} h_{2}} \text {, } \\
& F_{8,6}=-\frac{1+\mu_{3}}{1-\mu_{3}} \frac{n \pi}{b} \text {, } \\
& F_{8,7}=\frac{2}{1-\mu_{3}}\left(\left(\frac{n \pi}{b}\right)^{2}+\frac{G_{2}^{*}}{K_{3} h_{2}}+\frac{G_{4}^{*}}{K_{3} h_{4}}-\frac{m_{3} \omega^{* 2}}{K_{3}}\right), \\
& F_{8,11}=-\frac{2}{1-\mu_{3}} \frac{G_{4}^{*}}{K_{3} h_{4}}, \\
& F_{8,13}=-\frac{2}{1-\mu_{3}}\left(\frac{G_{2}^{*} h}{K_{3} h_{2}}-\frac{G_{4}^{*} h^{\prime}}{K_{3} h_{4}}\right) \frac{n \pi}{b}, \\
& F_{10,5}=-\frac{G_{4}^{*}}{K_{5} h_{4}} \\
& F_{10,9}=\frac{1-\mu_{5}}{2}\left(\frac{n \pi}{b}\right)^{2}+\frac{G_{4}^{*}}{K_{5} h_{4}}-\frac{m_{5} \omega^{* 2}}{K_{5}}, \\
& F_{10,12}=\frac{1+\mu_{1}}{2} \frac{n \pi}{b}, \\
& F_{10,14}=-\frac{G_{4}^{*} h^{\prime}}{K_{5} h_{4}} \\
& F_{12,7}=-\frac{2}{1-\mu_{5}} \frac{G_{4}^{*}}{K_{5} h_{4}}, \\
& F_{12,10}=-\frac{1+\mu_{5}}{1-\mu_{5}} \frac{n \pi}{b}, \\
& F_{12,11}=\frac{2}{1-\mu_{5}}\left(\left(\frac{n \pi}{b}\right)^{2}+\frac{G_{4}^{*}}{K_{5} h_{4}}-\frac{m_{5} \omega^{* 2}}{K_{5}}\right) \text {, } \\
& F_{16,6}=-\frac{1}{D_{1}+D_{3}+D_{5}}\left(\frac{h G_{2}^{*}}{h_{2}}-\frac{h^{\prime} G_{4}^{*}}{h_{4}}\right) \text {, } \\
& F_{16,7}=\frac{1}{D_{1}+D_{3}+D_{5}}\left(\frac{h G_{2}^{*}}{h_{2}}-\frac{h^{\prime} G_{4}^{*}}{h_{4}}\right) \frac{n \pi}{b}, \\
& F_{16,10}=-\frac{1}{D_{1}+D_{3}+D_{5}} \frac{h^{\prime} G_{4}^{*}}{h_{4}}, \\
& F_{16,11}=\frac{1}{D_{1}+D_{3}+D_{5}} \frac{h^{\prime} G_{4}^{*}}{h_{4}} \frac{n \pi}{b} \text {, } \\
& F_{16,13}=\frac{1}{D_{1}+D_{3}+D_{5}}\left(m \omega^{* 2}\right. \\
& \left.-\left(\frac{h^{2} G_{2}^{*}}{h_{2}}+\frac{h^{\prime 2} G_{4}^{*}}{h_{4}}\right)\left(\frac{n \pi}{b}\right)^{2}\right)-\left(\frac{n \pi}{b}\right)^{4}, \\
& F_{16,14}=2\left(\frac{n \pi}{b}\right)^{2}-\frac{1}{D_{1}+D_{3}+D_{5}}\left(\frac{h^{2} G_{2}^{*}}{h_{2}}\right. \\
& \left.+\frac{h^{\prime 2} G_{4}^{*}}{h_{4}}\right) \\
& A_{1,1}=A_{2,2}=A_{3,3}=A_{4,4}=A_{5,5}=A_{6,6}=A_{7,7} \\
& =A_{8,8}=A_{9,9}=A_{10,10}=A_{11,11}=A_{12,12} \\
& =A_{13,13}=A_{14,14}=A_{15,15}=1 \text {, } \\
& A_{2,3}=-\mu_{1} \frac{n \pi}{b}, \\
& A_{4,1}=\frac{n \pi}{b}, \\
& A_{6,7}=-\mu_{3} \frac{n \pi}{b}, \\
& A_{8,5}=\frac{n \pi}{b}, \\
& A_{10,11}=-\mu_{5} \frac{n \pi}{b}, \\
& A_{12,9}=\frac{n \pi}{b} \text {, } \\
& A_{14,13}=-\left(D_{1} \mu_{1}+D_{3} \mu_{3}+D_{5} \mu_{5}\right)\left(\frac{n \pi}{b}\right)^{2} \text {, } \\
& A_{14,15}=W\left(D_{1}+D_{3}+D_{5}\right),
\end{aligned}
$$




$$
\begin{aligned}
A_{16,1} & =\frac{G_{2} h}{h_{2}}, \\
A_{16,5} & =-\left(\frac{G_{2} h}{h_{2}}-\frac{G_{4} h^{\prime}}{h_{4}}\right), \\
A_{16,9} & =\frac{G_{4} h^{\prime}}{h_{4}}, \\
A_{16,14} & =-\left(G_{2}\left(\frac{h}{h_{2}}\right)^{2}+G_{4}\left(\frac{h^{\prime}}{h_{4}}\right)^{2}\right. \\
+ & \left(D_{1}\left(2-\mu_{1}\right)+D_{3}\left(2-\mu_{3}\right)+D_{5}\left(2-\mu_{5}\right)\right) \\
\left.\cdot\left(\frac{n \pi}{b}\right)^{2}\right) & \\
A_{16,15} & =D_{1}+D_{3}+D_{5} .
\end{aligned}
$$

The elements not listed in $F$ and $A$ are 0 .

\section{Competing Interests}

The authors declare that they have no competing interests.

\section{Acknowledgments}

This work was supported by the Natural Science Foundation of China (no. 50775225) and the Scientific and Technological Research Funds (no. 2014JY0061) from the Science \& Technology Department of Sichuan Province. This financial support is gratefully acknowledged.

\section{References}

[1] E. M. Kerwin, "Damping of flexural waves by a constrained viscoelastic layer," The Journal of the Acoustical Society of America, vol. 31, no. 7, pp. 952-962, 1959.

[2] D. Ross, E. E. Ungar, and E. M. Kerwin, "Flexural vibrations by means of viscoelastic laminate," ASME Structure Damping, pp. 48-87, 1959.

[3] D. J. Mead and S. Markus, "The forced vibration of a three-layer, damped sandwich beam with arbitrary boundary conditions," Journal of Sound and Vibration, vol. 10, no. 2, pp. 163-175, 1969.

[4] R. Rikards, A. Chate, and E. Barkanov, "Finite element analysis of damping the vibrations of laminated composites," Computers and Structures, vol. 47, no. 6, pp. 1005-1015, 1993.

[5] P. Cupiał and J. Nizioł, "Vibration and damping analysis of a three-layered composite plate with a viscoelastic mid-layer," Journal of Sound and Vibration, vol. 183, no. 1, pp. 99-114, 1995.

[6] Š. Markuš, "Damping properties of layered cylindrical shells, vibrating in axially symmetric modes," Journal of Sound and Vibration, vol. 48, no. 4, pp. 511-524, 1976.

[7] H. H. Pan, "Axisymmetrical vibrations of a circular sandwich shell with a viscoelastic core layer," Journal of Sound and Vibration, vol. 9, no. 2, pp. 338-348, 1969.

[8] N. Alam and N. T. Asnani, "Vibration and damping analysis of a multilayered cylindrical shell, part I: theoretical analysis," AIAA Journal, vol. 22, no. 6, pp. 803-810, 1984.
[9] N. Alam and N. T. Asnani, "Vibration and damping analysis of a multilayered cylindrical shell, part II: numerical results," AIAA Journal, vol. 22, no. 7, pp. 975-981, 1984.

[10] R. A. S. Moreira, J. D. Rodrigues, and A. J. M. Ferreira, "A generalized layerwise finite element for multi-layer damping treatments," Computational Mechanics, vol. 37, no. 5, pp. 426-444, 2006.

[11] M. Matter, T. Gmür, J. Cugnoni, and A. Schorderet, "A PSDT shell finite element formulation including structural damping," Computers and Structures, vol. 88, no. 15-16, pp. 902-908, 2010.

[12] K. Amichi and N. Atalla, "A new 3d finite element for sandwich beams with a viscoelastic core," Journal of Vibration and Acoustics, vol. 131, no. 2, Article ID 021010, 2009.

[13] Z. Xie and W. S. Shepard Jr., "An enhanced beam model for constrained layer damping and a parameter study of damping contribution," Journal of Sound and Vibration, vol. 319, no. 3-5, pp. 1271-1284, 2009.

[14] J.-D. Chazot, B. Nennig, and A. Chettah, "Harmonic response computation of viscoelastic multilayered structures using a ZPST shell element," Computers and Structures, vol. 89, no. 2324, pp. 2522-2530, 2011.

[15] F. Abdoun, L. Azrar, E. M. Daya, and M. Potier-Ferry, "Forced harmonic response of viscoelastic structures by an asymptotic numerical method," Computers and Structures, vol. 87, no. 1-2, pp. 91-100, 2009.

[16] J.-M. Yang, X.-D. Zhong, and Y.-Y. Zhao, "Strain energy and damping analysis of composite laminates with two interleaved viscoelastic layers," Engineering Mechanics, vol. 27, no. 3, pp. 212-216, 2010.

[17] M.-J. Li, G.-W. Liu, and Y.-W. Xu, "Parameter effects of the main controlled anisotropic layer on structural damping of alternately laminated damped structures," Acta Material Composite Sinica, vol. 23, pp. 180-184, 2006.

[18] E.-Q. Li, G.-J. Tang, Y.-J. Lei, and D.-K. Li, "Dynamic analysis of constrained layer damping plate by the transfer function method," Journal of National University of Defense Technology, vol. 30, no. 1, pp. 5-9, 2008.

[19] Y. Xiang, Y.-Y. Huang, J. Lu, L.-Y. Yuan, and S.-Z. Zou, "New matrix method for analyzing vibration and damping effect of sandwich circular cylindrical shell with viscoelastic core," Applied Mathematics and Mechanics, vol. 29, no. 12, pp. 15871600, 2008.

[20] J. Lu, Y. Xiang, Y. Huang, X. Li, and Q. Ni, “Transfer matrix method for analyzing vibration and damping characteristics of rotational shell with passive constrained layer damping treatment," Acta Mechanica Solida Sinica, vol. 23, no. 4, pp. 297-311, 2010.

[21] C. D. Johnson and D. A. Kienholz, "Finite element prediction of damping in structures with constrained viscoelastic layers," AIAA Journal, vol. 20, no. 9, pp. 1284-1290, 1982. 


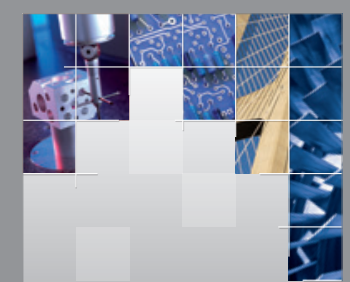

\section{Enfincering}
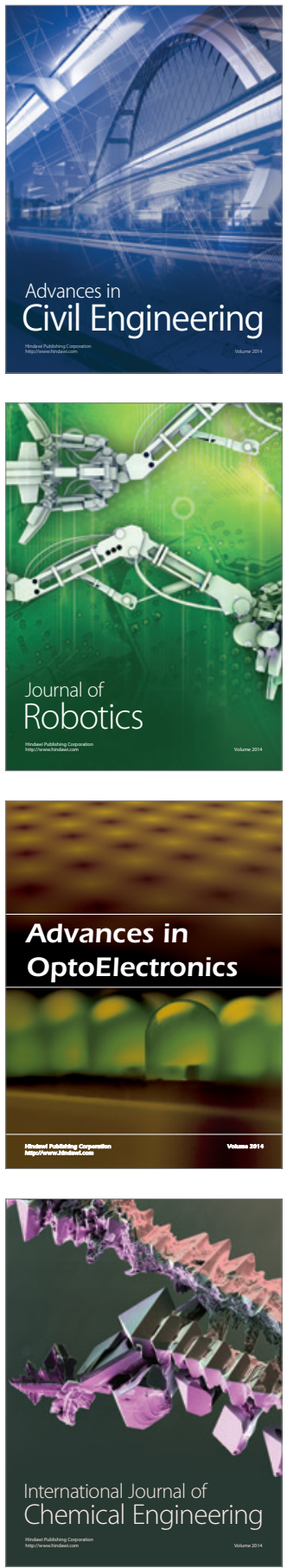

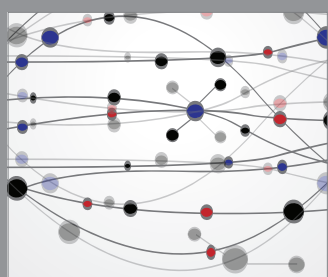

The Scientific World Journal

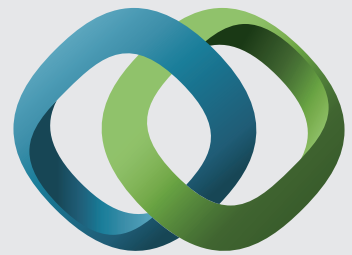

\section{Hindawi}

Submit your manuscripts at

http://www.hindawi.com
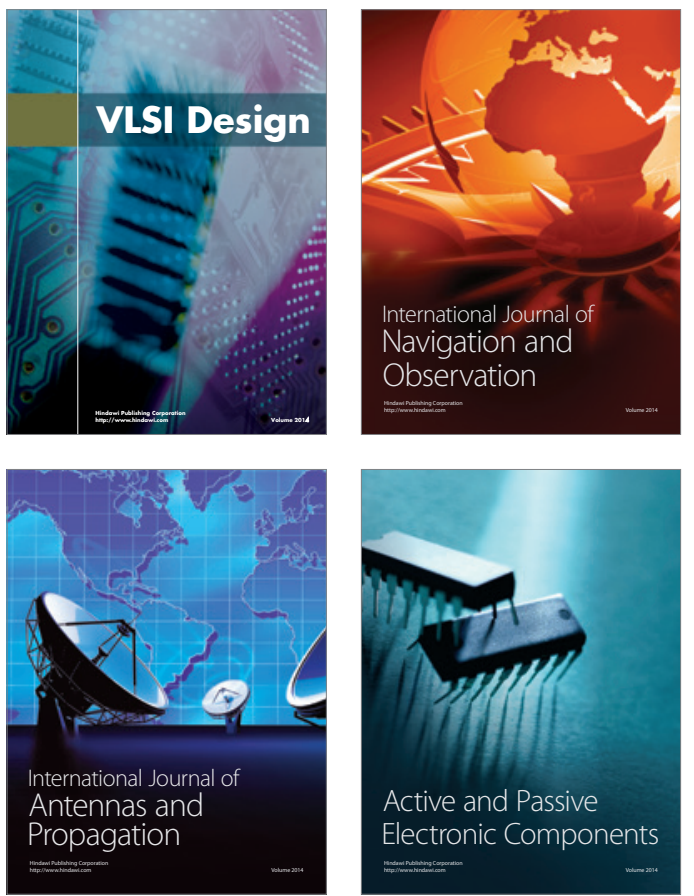
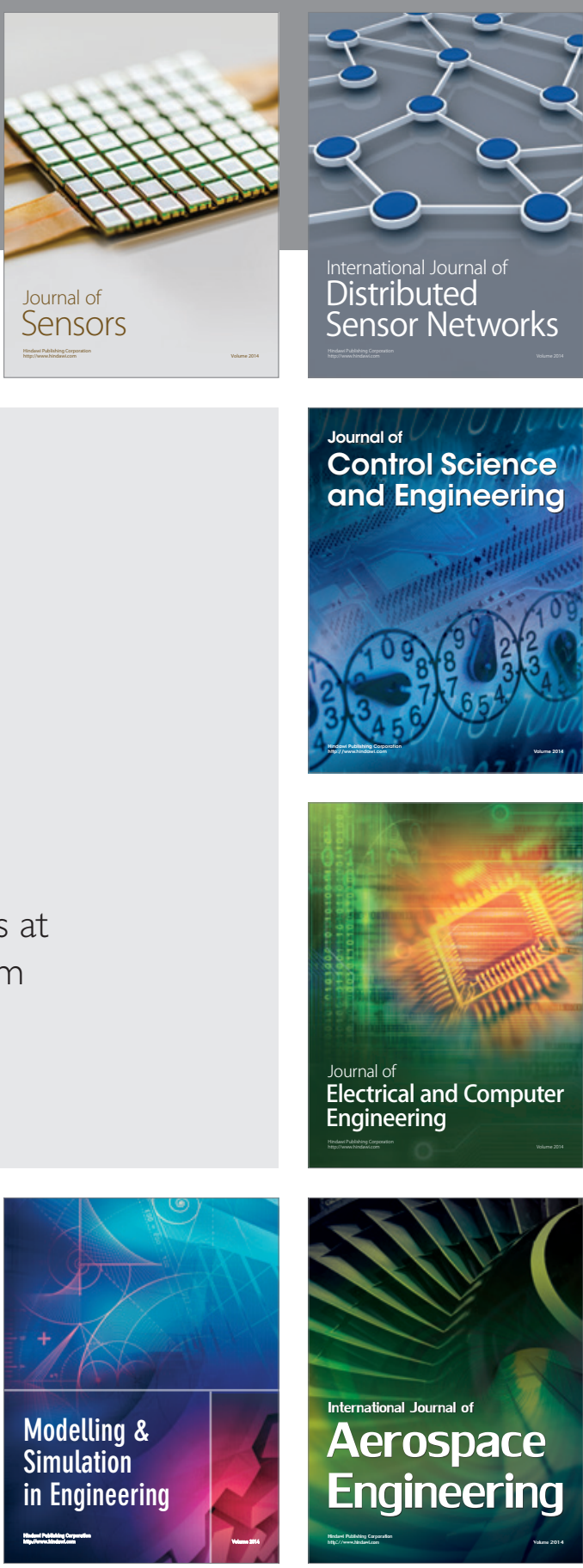

International Journal of

Distributed

Sensor Networks

Journal of

Control Science

and Engineering
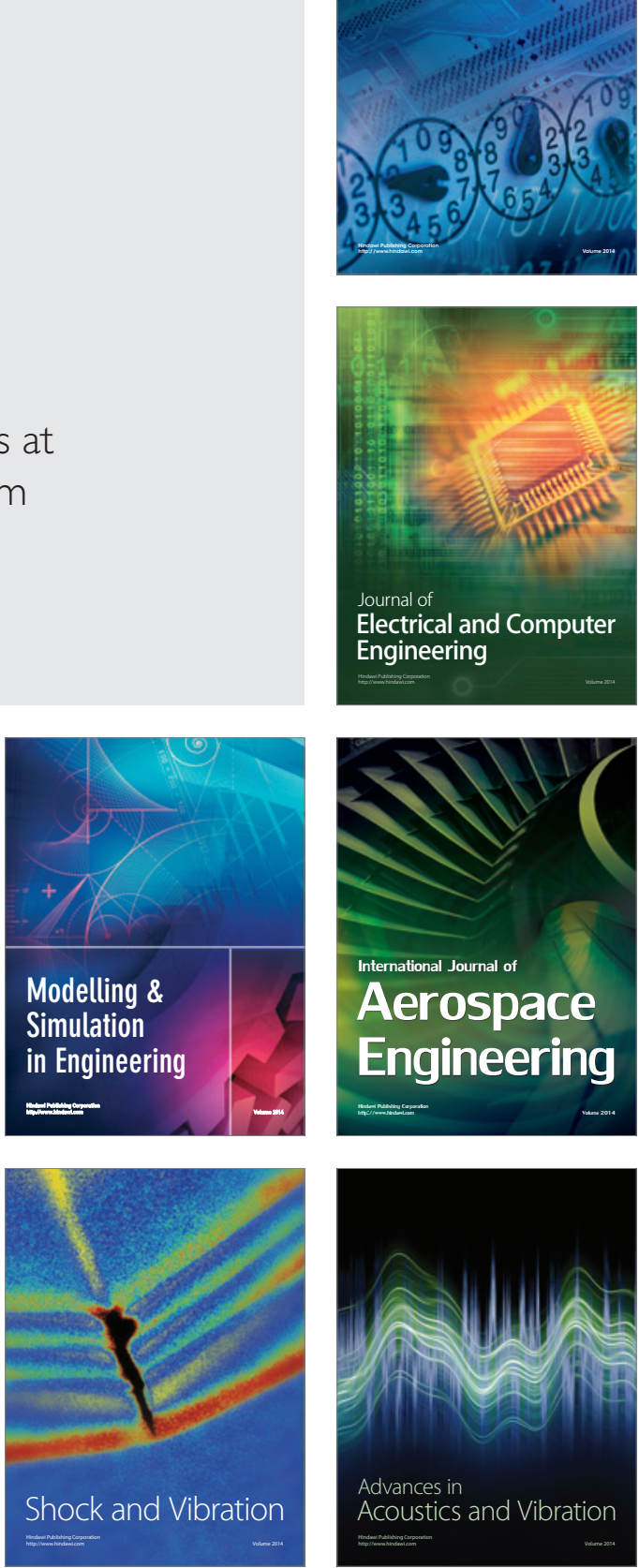